\title{
Les «déclarations éthiques de renonciation» mettent en péril le principe de solidarité de l'assurance-maladie
}

Aujourd'hui, la renonciation à l'interruption de grossesse peut se monnayer au prix fort. En signant une «déclaration éthique de renonciation», on peut profiter de réductions sur les primes. La Commission nationale d'éthique pour la médecine humaine critique cette pratique.

Commission nationale d'éthique pour la médecine humaine
Correspondance:

Sibylle Schürch, docteur en droit Commission nationale d'éthique pour la médecine humaine Office de la santé publique Seilerstrasse 8

CH-3003 Berne

Tél. 0313249365

Fax 0313226233
En Suisse, certaines associations proposent des contrats spéciaux avec des caisses-maladie qui accordent des réductions de primes contre la renonciation à certaines prestations considérées comme étant moralement condamnables. Parmi elles figurent l'interruption de grossesse, certaines méthodes de diagnostic prénatal, la fécondation in-vitro et la thérapie de substitution de la drogue par la méthadone.

\section{La solidarité est refusée à ceux qui pensent différemment}

La Commission nationale d'éthique est préoccupée par ces contrats spéciaux. Invoquant des convictions morales, les personnes qui renoncent à certaines prestations obtiennent des réductions de primes d'assurance-maladie; par-là, elles se désolidarisent des autres. Cette démarche va à l'encontre des fondements éthiques de l'assurance-maladie.

\section{Les informations portant sur une rupture de contrat sont insuffisantes}

Il n'est pas certain que les membres des associations aient été suffisamment informés. L'information selon laquelle ils peuvent prétendre aux prestations de l'assurance de base malgré la déclaration de renonciation ne leur a été transmise qu'en partie. Un simple avis de révocation suffit, et un changement de caisse n'est pas nécessaire. Comme cette indication fait défaut, on suggère que, dans le cas d'une interruption de grossesse par exemple, les assurées seront confrontées à des conséquences financières.

\section{Les enfants ne doivent pas être incités à signer de tels contrats}

Or, les parents sont invités à demander à leurs enfants de 13 ou de 16 ans de souscrire une déclaration de renonciation. Pour la commission, il est très problématique de voir des mineurs incités à signer des contrats ayant des conséquences financières.

\section{La loi doit exclure la renonciation à des prestations}

Le droit fédéral prévoit fondamentalement une renonciation à des prestations. Mais ce principe général n'a pas été posé en vue d'autoriser des renonciations aux prestations de l'assurance de base. La commission recommande d'exclure la renonciation volontaire à des prestations de l'assurance de base.

Prise de position no 12/2006: www.nek-cne.ch. 